\title{
Molecular detection and identification of piroplasms (Babesia spp. and Theileria spp.) and Anaplasma phagocytophilum in questing ticks from northwest Spain
}

\author{
Susana Remesar \\ Universidade de Santiago de Compostela Facultad de Veterinaria \\ Pablo Diaz ( $\sim$ pablo.diaz@usc.es ) \\ Universidade de Santiago de Compostela https://orcid.org/0000-0003-2445-1095 \\ Alberto Prieto \\ Universidade de Santiago de Compostela Facultad de Veterinaria \\ David García-Dios \\ Universidade de Santiago de Compostela Facultad de Veterinaria \\ Rosario Panadero \\ Universidade de Santiago de Compostela Facultad de Veterinaria \\ Gonzalo Fernández \\ Universidade de Santiago de Compostela Facultad de Veterinaria \\ Emmanuele Brianti \\ Universita degli Studi di Messina \\ Pablo Díez-Baños \\ Universidade de Santiago de Compostela Facultad de Veterinaria \\ Patrocinio Morrondo \\ Universidade de Santiago de Compostela Facultad de Veterinaria \\ Ceferino Manuel López \\ Universidade de Santiago de Compostela Facultad de Veterinaria
}

\section{Research}

Keywords: Babesia venatorum, Babesia microti, Theileria sp. OT3, Anaplasma phagocytophilum, questing Ixodes ricinus, Spain

Posted Date: January 28th, 2020

DOI: https://doi.org/10.21203/rs.2.21993/v1

License: (c) (1) This work is licensed under a Creative Commons Attribution 4.0 International License. Read Full License

Version of Record: A version of this preprint was published at Medical and Veterinary Entomology on August 5th, 2020. See the published version at https://doi.org/10.1111/mve.12468. 


\section{Abstract}

Background: Ticks can transmit a wide range of pathogens; some of them are regarded as emerging or re-emerging pathogens causing a significant impact on human and animal health.

Methods: In order to determine prevalence and zoonotic potential of Anaplasma spp., Candidatus Neoehrlichia mikurensis and piroplasms in questing ticks from north-western Spain, 1,056 Ixodes ricinus, nineteen Dermacentor marginatus, seventeen Dermacentor reticulatus, twelve Ixodes frontalis and a single Ixodes acuminatus were molecularly analysed. Also, 23 pools of I. ricinus larvae were investigated for the presence of piroplasms. Anaplasma and piroplasm DNA was firstly detected using two commercial qPCR assays. Samples positive to Anaplasma spp. were confirmed and identified at species level by sequence analysis of the groESL, $16 \mathrm{~S}$ rRNA and $m s p 2$ genes. Those samples negative to Anaplasma spp. groESL were pooled and processed to detect a fragment of the groESL gene of $\mathrm{Ca}$. N. mikurensis. qPCR piroplasm positive samples were molecularly identified at the species level by partial sequencing of the $18 \mathrm{~S}$ rRNA and ITS1 genes.

Results: Four pathogen species were detected in individual I. ricinus, namely Babesia venatorum (1.5\%), A. phagocytophilum (0.7\%), Babesia microti (0.3\%) and Theileria sp. OT3 (0.2\%). Babesia venatorum was also identified in a single I. ricinus larvae pool (maximum likelihood estimation $0.6 \%$ ) whereas no $I$. ricinus pools were positive to $\mathrm{Ca}$. N. mikurensis. In addition, one I. frontalis (8.3\%) tested positive to A. phagocytophilum.

Conclusions: Our results revealed that a low percentage of I. ricinus from northwest Spain were infected with A. phagocytophilum and piroplasms. Since a potentially pathogenic variant of $A$. phagocytophilum and two zoonotic Babesia species were detected, these results may have public health concern. Since the vector of Theileria sp. OT3 remains unknown, its identification in I. ricinus is especially interesting; nevertheless, further investigations are needed to unravel the role of $I$. ricinus in the transmission of this Theileria species.

\section{Background}

Ticks are considered, after mosquitoes, the second vector in terms of public health importance, being able to transmit a wide range of pathogens [1]. Although Lyme borreliosis and tick-borne encephalitis are the most common tick-borne diseases in Europe, the negative impact of other tick-borne pathogens causing diseases on human and animals should also be considered [2]. Many of these pathogens, including Anaplasma phagocytophilum, Candidatus Neoehrlichia mikurensis and some Babesia species such as Babesia venatorum and Babesia microti, are regarded as emerging or re-emerging pathogens with a significant impact on human health [3].

Ixodes ricinus has been identified as the main vector of A. phagocytophilum and Ca. N. mikurensis, showing prevalence up to $33.9 \%$ and $10.5 \%$, respectively, in questing ticks throughout Europe [4,5]. That tick species does not act as reservoir for both pathogens since no transovarial transmission has been currently reported [6]. In this respect, hedgehogs and other rodent species have been identified as suitable reservoir hosts for Ca. N. mikurensis [7, 8]. In contrast, the epidemiological cycle of A. phagocytophilum is complex due to the existence of some variants/ecotypes related to different hosts and vector species. Thus, analysis at different genetic markers should be performed in order to identify the genetic variants and to determine their zoonotic potential, being groEL and 16S rRNA two of the most used genes [9]. Up to date, four A. phagocytophilum ecotypes (I to IV) have been identified at the groEL gene, and the presence of a thymine in the nucleotide position 724 of this gene has been identified as a predictor of pathogenicity [10, 11]. In addition, more than ten variants have been described at the 16S rRNA gene, although only three ("A", “B" and "W") have been identified in cases of granulocytic anaplasmosis [12-14].

Ixodes ricinus has been also identified as the most important vector of the zoonotic Babesia divergens and B. venatorum in several European countries although it has been reported that other tick species such as Dermacentor reticulatus and Ixodes persulcatus could play a role as vectors [15]. In contrast, Ixodes trianguliceps is the main vector of $\mathrm{B}$. microti which is considered the main etiological agent of human babesiosis in Northern America, although it was also reported in Europe [16]. Domestic cattle and wild ruminants such as roe deer are the major reservoirs of B. divergens and B. venatorum, respectively; in contrast, the main reservoir of B. microti are rodents [17].

Theileria spp. are transmitted by numerous ixodid species belonging to several genera such as Amblyomma, Haemaphysalis, Hyalomma and Rhipicephalus [18]. This piroplasm can infect wild ungulates and a wide range of domestic animals such as cattle, sheep, goats and horses, some of which can develop clinical disease [19]. However, no Theileria species have been currently identified as zoonotic [20].

Previous investigations carried out in questing I. ricinus from Spain reported A. phagocytophilum prevalence up to 20.5\% [21]. Nevertheless, the number of studies using different genetic markers for characterizing A. phagocytophilum isolates is scarce $[22,23]$ and therefore information on both animal reservoirs and ecology of Anaplasma spp. in this country is still limited. As regards to Ca. N. mikurensis, only a single investigation was performed in Spain, showing a low prevalence (1\%) in I. ricinus collected from cattle in northern areas [24]. In the same way, the information available on the presence of piroplasms in questing ticks from this country is limited [25].

Considering that a recent study has shown that I. ricinus, the main vector of some of these pathogens, is the predominant tick species in north-western Spain [26], the presence of both bacteria (Anaplasma spp. and Ca. N. mikurensis) and piroplasms (Babesia spp. and Theileria spp.) in questing ticks collected from that region was assessed using molecular methods. In addition, A. phagocytophilum positive samples were further analysed in order to identify the ecotypes/variants and to assess their possible pathogenicity for human. Findings of the current study provide useful information on the prevalence of these pathogens among tick species as well as their significance for public and animal health.

\section{Methods}




\section{Study area, tick collection and identification}

Field studies were conducted from November 2015 to October 2017 in three forest areas (mountain, coastal and plateau) of Galicia, a region located in the northwest of Spain $\left(43^{\circ} 47^{\prime}-41^{\circ} 49^{\prime} \mathrm{N}, 6^{\circ} 42^{\prime}-9^{\circ} 18^{\prime} \mathrm{W}\right)$. The main weather features of each sampling area as well as the tick sampling protocols were previously reported [26]. During 24 months, tick collection was monthly performed by flagging along three selected $300 \mathrm{~m}$ transects; then, ticks were identified to species level using previously described morphological keys [27].

\section{DNA extraction and detection of pathogens}

A total of 1,056 I. ricinus (652 nymphs, 202 females and 202 males), twelve I. frontalis nymphs, seventeen D. reticulatus (ten females and seven males), nineteen D. marginatus (fifteen females and four males) and a single I. acuminatus male were individually processed to detect the presence of Anaplasma spp., Babesia spp. and Theileria spp. Since some piroplasm species could be transmitted transovarially, 23 pools including $165 \mathrm{I}$. ricinus larvae were also performed. Ixodes ricinus larvae were not frequently collected, but when found, all specimens were captured in a single location point and considered offspring of the same female tick; depending on the number of larvae collected in a single sampling, each pool consisted of between two and ten specimens.

DNA was extracted from both individual and pooled ticks using a commercial kit (High Pure PCR Template Preparation Kit, Roche Diagnostics GmbH®, Mannheim, Germany) following the manufacturer's instructions. Previously, tick tissues were disrupted using a MagNaLyser Instrument (Roche Diagnostic, Manheim, Germany) at 6,000 rpm during 60 seconds. Presence of Anaplasma and piroplasm DNA was firstly detected using two qPCR commercial kits (EXOone Anaplasma spp. and EXOone Piroplasms ${ }^{\circledR}$, Exopol, Zaragoza, Spain). In order to identify the species present and their zoonotic potential, all qPCRpositive samples were selected and further analysed by specific conventional PCRs targeting the groESL, 16S rRNA and msp2 partial genes of Anaplasma spp. and the 18S rRNA and ITS1 partial genes of Babesia spp. and Theileria spp. following previously described protocols (Table 1). Finally, DNA from individual I. ricinus was pooled in groups of ten nymphs, females or males to detect Ca. N. mikurensis. Pools were then subjected to a conventional PCR targeting the groESL (Liz et al., 2002). Since this PCR also amplifies Anaplasma spp., qPCR-positive Anaplasma samples were not included in the pools.

Table 1

Primers and protocols used for detection and identification of Anaplasma spp., Candidatus Neoehrlichia mikurensis, Babesia spp. and Theileria spp.

\begin{tabular}{|c|c|c|c|c|}
\hline Gene target & $\begin{array}{l}\text { Primer } \\
\text { name }\end{array}$ & Primer sequence $5^{\prime}-3^{\prime}$ & $\begin{array}{l}\text { Fragment } \\
\text { size }\end{array}$ & Reference \\
\hline \multirow{4}{*}{$\begin{array}{l}\text { GroESL of Anaplasma spp. and Candidatus Neoehrlichia } \\
\text { mikurensis }\end{array}$} & HS1 & AIT GGG CTG GTA ITG AAA T & \multirow[t]{4}{*}{1,297 bp } & \multirow[t]{4}{*}{ [57] } \\
\hline & HS6 & CCI CCI GGI ACI AIA CCT TC & & \\
\hline & HS43 & ATW GCW AAR GAA GCA TAG TC & & \\
\hline & HSVR & CTC AAC AGC AGC TCT AGT AGC & & \\
\hline \multirow[t]{4}{*}{ 16sRNA of Anaplasma spp. } & ge3a & $\begin{array}{l}\text { CAC ATG CAA GTC GAA CGG ATT ATT } \\
\text { C }\end{array}$ & \multirow[t]{4}{*}{$546 \mathrm{bp}$} & \multirow[t]{4}{*}{ [28] } \\
\hline & ge10r & $\begin{array}{l}\text { TTC CGT TAA GAA GGA TCT AAT CTC } \\
\text { C }\end{array}$ & & \\
\hline & ge9f & $\underset{T}{\text { AAC GGA TTA TTC TTT ATA GCT TGC }}$ & & \\
\hline & ge2 & GGC AGT ATT AAA AGC AGC TCC AGG & & \\
\hline \multirow[t]{2}{*}{ msp2 of Anaplasma spp. } & msp2-3F & CCA GCG TTT AGC AAG ATA AGA G & \multirow[t]{2}{*}{$334 \mathrm{bp}$} & \multirow[t]{2}{*}{ [59] } \\
\hline & msp2-3R & GCC CAG TAA CAA CAT CAT AAG C & & \\
\hline \multirow[t]{4}{*}{ 18srRNA of Babesia spp. and Theileria spp. } & RIB-19 & $\begin{array}{l}\text { CGG GAT CCA ACC TGG TTG ATC CTG } \\
\text { C }\end{array}$ & \multirow[t]{4}{*}{$430 \mathrm{bp}$} & \multirow[t]{4}{*}[60,61]{} \\
\hline & RIB-20 & CCG AAT TCC TTG TTA CGA CTT CTC & & \\
\hline & BAB-rumF & ACC TCA CCA GGT CCA GAC AG & & \\
\hline & BAB-rumR & GTA CAA AGG GCA GGG ACG TA & & \\
\hline \multirow[t]{2}{*}{ ITS1 of Babesia spp. and Theileria spp. } & BAITS1-F & CGAGTGATCCGGTGAATTATTC & \multirow[t]{2}{*}{$600 \mathrm{bp}$} & \multirow[t]{2}{*}[39,62]{} \\
\hline & BAITS1-R & СCTTCATCGTTGTGTGAGCC & & \\
\hline
\end{tabular}

Positive samples were sequenced in both directions using an ABI 3730xI sequencer (Applied Biosystems, Foster City, California, USA) at the Sequencing and fragment analysis Unit of the University of Santiago de Compostela. Sequences were aligned and edited using ChromasPro 2.1.4. (Technelysium, Brisbane, Australia) and consensus sequences were scanned against the GenBank database using the Basic Local Alignment Search Tool (BLAST; http://blast.ncbi.nlm.nih.gov/Blast.cgi). The zoonotic potential of A. phagocytophilum was studied comparing the sequences at groEL and $16 \mathrm{~S}$ rRNA partial genes to reference sequences of $A$. phagocytophilum strains considered pathogenic for humans $[28,29]$.

Unique partial sequences obtained in this study were deposited in GenBank under accession numbers MK341070-MK341076 and MN726523. 
Maximum likelihood estimation (MLE) was used to estimate the prevalence of piroplasms in I. ricinus larvae pools as previously reported [30]. The possible influence of some variables (I. ricinus development stage, sampling area, year and season of sampling) in the prevalence of the pathogens was analysed by Chi-square test; the level of significance was set at $\mathrm{P}$ values $<0.05$. All statistical analyses were performed using the statistical software R 3.4 .3 [31].

\section{Results}

Seven I. ricinus ( $0.7 \%)$ and a single I. frontalis nymph (8.3\%) resulted positive to Anaplasma qPCR. All qPCR-positive samples were also positive to all conventional PCRs performed. Using qPCR, piroplasm DNA was detected in 21 individual I. ricinus (2.0\%) and in a single I. ricinus larvae pool (MLE = 0.6\%); all these positives were also confirmed by 18S rRNA and ITS1 PCR. Anaplasma or piroplasm DNA was not found in the other tick species analysed (D. marginatus, D. reticulatus and I. acuminatus) and no Ca. N. mikurensis positive pools were detected. No ticks were positive to more than one pathogen.

Sequence analysis allowed the identification of A. phagocytophilum in all Anaplasma positive samples (Table 2). In addition, three piroplasm species, namely B. venatorum (16/21), B. microti (3/21) and Theileria sp. OT3 (2/21), were also identified (Table 2). Babesia venatorum was also identified in the single positive larvae pool $(1 / 23 ; 4.3 \%$; MLE $=0.62 \%)$. No significant differences in A. phagocytophilum or piroplasm species prevalences when considering the tick development stages, sampling areas, seasons and years of study (Table 2) were found.

Table 2

Prevalence of Anaplasma, Babesia and Theileria species in Ixodes ricinus from northwestern Spain when considering different variable

\begin{tabular}{|c|c|c|c|c|c|c|c|c|c|c|c|c|c|}
\hline & & \multicolumn{3}{|c|}{ Tick development stage } & \multicolumn{3}{|c|}{ Sampling area } & \multicolumn{4}{|c|}{ Season of sampling } & \multicolumn{2}{|c|}{ Year of samp } \\
\hline & & Nymphs & Female & Male & Plateau & Mountain & Coastal & Spring & Summer & Autumn & Winter & Year 1 & Year \\
\hline \multicolumn{14}{|l|}{ Anaplasma spp. } \\
\hline \multirow[t]{2}{*}{$\begin{array}{l}\text { A. } \\
\text { phagocytophilum }\end{array}$} & Ir & $\begin{array}{l}4 / 652 \\
(0.61 \%)\end{array}$ & $\begin{array}{l}2 / 202 \\
(0.99 \%)\end{array}$ & $\begin{array}{l}1 / 202 \\
(0.50 \%)\end{array}$ & $\begin{array}{l}1 / 272 \\
(0.37 \%)\end{array}$ & $\begin{array}{l}4 / 372 \\
(1.08 \%)\end{array}$ & $\begin{array}{l}2 / 412 \\
(0.49 \%)\end{array}$ & $\begin{array}{l}3 / 437 \\
(0.69 \%)\end{array}$ & $\begin{array}{l}1 / 259 \\
(0.39 \%)\end{array}$ & $\begin{array}{l}2 / 148 \\
(1.35 \%)\end{array}$ & $\begin{array}{l}1 / 212 \\
(0.47 \%)\end{array}$ & $\begin{array}{l}4 / 534 \\
(0.75 \%)\end{array}$ & $\begin{array}{l}3 / 52 \\
(0.57\end{array}$ \\
\hline & If & $\begin{array}{l}1 / 12 \\
(8.33 \%)\end{array}$ & - & - & $\begin{array}{l}0 / 8 \\
(0 \%)\end{array}$ & $\begin{array}{l}0 / 2 \\
(0 \%)\end{array}$ & $\begin{array}{l}1 / 2 \\
(50 \%)\end{array}$ & $\begin{array}{l}0 / 2 \\
(0 \%)\end{array}$ & - & $\begin{array}{l}1 / 4 \\
(25 \%)\end{array}$ & $\begin{array}{l}0 / 6 \\
(0 \%)\end{array}$ & $\begin{array}{l}0 / 5 \\
(0 \%)\end{array}$ & $\begin{array}{l}1 / 7 \\
(14.2\end{array}$ \\
\hline \multicolumn{14}{|l|}{ Babesia spp. } \\
\hline B. venatorum & Ir & $\begin{array}{l}11 / 652 \\
(1.69 \%)\end{array}$ & $\begin{array}{l}3 / 202 \\
(1.49 \%)\end{array}$ & $\begin{array}{l}2 / 202 \\
(0.99 \%)\end{array}$ & $\begin{array}{l}3 / 272 \\
(1.10 \%)\end{array}$ & $\begin{array}{l}4 / 372 \\
(1.08 \%)\end{array}$ & $\begin{array}{l}9 / 412 \\
(2.18 \%)\end{array}$ & $\begin{array}{l}5 / 437 \\
(1.14 \%)\end{array}$ & $\begin{array}{l}5 / 259 \\
(1.93 \%)\end{array}$ & $\begin{array}{l}2 / 148 \\
(1.35 \%)\end{array}$ & $\begin{array}{l}4 / 212 \\
(1.89 \%)\end{array}$ & $\begin{array}{l}7 / 534 \\
(1.31 \%)\end{array}$ & $\begin{array}{l}9 / 52 \\
(1.72\end{array}$ \\
\hline B. microti & Ir & $\begin{array}{l}3 / 652 \\
(0.46 \%)\end{array}$ & $\begin{array}{l}0 / 202 \\
(0 \%)\end{array}$ & $\begin{array}{l}0 / 202 \\
(0 \%)\end{array}$ & $\begin{array}{l}0 / 272 \\
(0 \%)\end{array}$ & $\begin{array}{l}0 / 372 \\
(0 \%)\end{array}$ & $\begin{array}{l}3 / 412 \\
(0.73 \%)\end{array}$ & $\begin{array}{l}0 / 437 \\
(0 \%)\end{array}$ & $\begin{array}{l}0 / 259 \\
(0 \%)\end{array}$ & $\begin{array}{l}2 / 148 \\
(1.35 \%)\end{array}$ & $\begin{array}{l}1 / 212 \\
(0.47 \%)\end{array}$ & $\begin{array}{l}3 / 534 \\
(0.56 \%)\end{array}$ & $\begin{array}{l}0 / 52 \\
(0 \%)\end{array}$ \\
\hline TOTAL & & $\begin{array}{l}14 / 652 \\
(2.15 \%)\end{array}$ & $\begin{array}{l}3 / 202 \\
(1.49 \%)\end{array}$ & $\begin{array}{l}2 / 202 \\
(0.99 \%)\end{array}$ & $\begin{array}{l}3 / 272 \\
(1.10 \%)\end{array}$ & $\begin{array}{l}4 / 372 \\
(1.08 \%)\end{array}$ & $\begin{array}{l}12 / 412 \\
(2.91 \%)\end{array}$ & $\begin{array}{l}5 / 437 \\
(1.14 \%)\end{array}$ & $\begin{array}{l}5 / 259 \\
(1.93 \%)\end{array}$ & $\begin{array}{l}4 / 148 \\
(2.70 \%)\end{array}$ & $\begin{array}{l}5 / 212 \\
(2.36 \%)\end{array}$ & $\begin{array}{l}10 / 534 \\
(1.87 \%)\end{array}$ & $\begin{array}{l}9 / 52 \\
(1.72\end{array}$ \\
\hline \multicolumn{14}{|l|}{ Theileria spp. } \\
\hline Theileria sp. ОТ3 & Ir & $\begin{array}{l}2 / 652 \\
(0.31 \%)\end{array}$ & $\begin{array}{l}0 / 202 \\
(0 \%)\end{array}$ & $\begin{array}{l}0 / 202 \\
(0 \%)\end{array}$ & $\begin{array}{l}1 / 272 \\
(0.37 \%)\end{array}$ & $\begin{array}{l}1 / 372 \\
(0.27 \%)\end{array}$ & $\begin{array}{l}0 / 412 \\
(0 \%)\end{array}$ & $\begin{array}{l}2 / 437 \\
(0.46 \%)\end{array}$ & $\begin{array}{l}0 / 259 \\
(0 \%)\end{array}$ & $\begin{array}{l}0 / 148 \\
(0 \%)\end{array}$ & $\begin{array}{l}0 / 212 \\
(0 \%)\end{array}$ & $\begin{array}{l}0 / 534 \\
(0 \%)\end{array}$ & $\begin{array}{l}2 / 52 \\
(0.3 \varepsilon\end{array}$ \\
\hline
\end{tabular}

Nucleotide sequences of A. phagocytophilum showed a 99.3-100\% homology when compared to reference sequences at groESL, 16S rRNA and msp2 genes. Sequence analysis at the groESL gene showed that, of the eight positive samples, three were included in clade I and five in clade II (Table 3 ). Most of the sequences obtained for the groESL gene (5/8) were identical to other deposited GenBank sequences originated from roe deer captured in France (KJ832450) and Czech Republic (AY22046), and from I. ricinus collected from a bird (KF031393) and a roe deer (EU552912) from Italy. Nevertheless, all A. phagocytophilum groESL sequences showed up to 55 polymorphisms with respect to sequence U96728, associated with human anaplasmosis [29] (Table 3). The study of 16S rRNA partial gene of A. phagocytophilum (Table 4) revealed that six out of eight isolates were included within variants "W", "X" and "Y", whereas two did not coincide with any known variant. Most 16S rRNA sequences (5/8) were identical to sequences obtained from a roe deer in Czech Republic (EU839847), a moose in Sweden (KC800983) and I. ricinus feeding on a wolf (KY404195) and a bird (JN181070) in Italy and Norway, respectively (Table 4). All these sequences showed one to three single nucleotide polymorphisms with regards to variant "B" strain U02521 which was identified in clinical cases [12]. Finally, all msp2 sequences were identical to A. phagocytophilum sequences obtained from questing I. ricinus ticks from Ukraine (KX591651) and Italy (JQ669948) as well as from a dog from Poland (DQ519568) and from the A. phagocytophilum laboratory strain Norway variant 2 (CP015376). 
groEL nucleotide differences of Anaplasma phagocytophilum positive samples from questing ticks in north-western Spain when com

Clade, tick development stage and

ID groEL nucleotide position (bp)

$\begin{array}{llllllllllllllllllllllllllllll}2 & 6 & 2 & 2 & 2 & 2 & 3 & 3 & 3 & 4 & 4 & 5 & 6 & 6 & 6 & 6 & 7 & 7 & 7 & 7 & 7 & 7 & 7 & 7 & 7 & 7 & 7 & 7 \\ 9 & 0 & 8 & 8 & 9 & 9 & 2 & 2 & 8 & 5 & 6 & 3 & 1 & 2 & 9 & 9 & 0 & 2 & 2 & 2 & 2 & 2 & 3 & 4 & 4 & 5 & 6 & 8 \\ & & 2 & 5 & 1 & 6 & 4 & 7 & 1 & 0 & 5 & 7 & 5 & 7 & 0 & 7 & 5 & 0 & 1 & 3 & 4 & 9 & 2 & 1 & 4 & 6 & 8 & 0\end{array}$

U96728

A C

A $\quad G \quad A \quad G \quad T \quad A \quad T \quad$ G $\quad$ C

I. ricinus

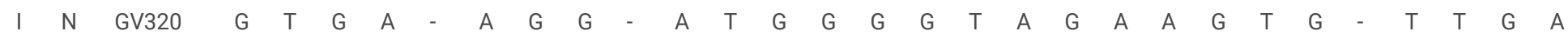

I M GV348

II F GV036

II F GV450

II N GV566

II N GV567

II N GV898

I. frontalis

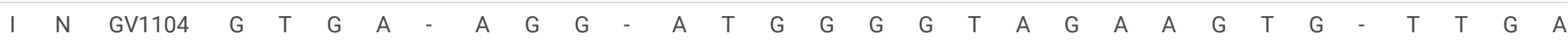

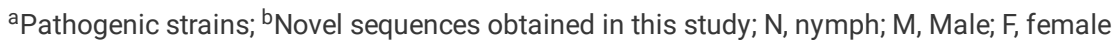

Table 4

16S rRNA nucleotide differences of Anaplasma phagocytophilum positive samples from questing ticks in north-western Spain when compared to reference sequences related to clinical cases. Hyphens indicate the presence of the same nucleotide as in the reference sequence

\begin{tabular}{|c|c|c|c|c|c|c|c|c|c|c|}
\hline \multirow{2}{*}{\multicolumn{3}{|c|}{$\begin{array}{l}\text { Variant, tick development stage and } \\
\text { ID }\end{array}$}} & \multicolumn{7}{|c|}{ 16S rRNA nucleotide position (bp) } & \multirow[t]{2}{*}{ Sequence showing $100 \%$ homology } \\
\hline & & & 75 & 76 & 77 & 78 & 82 & 84 & 376 & \\
\hline B & & U02521 & $\mathrm{T}$ & A & A & A & $\mathrm{T}$ & G & G & \\
\hline \multicolumn{11}{|c|}{ I. ricinus } \\
\hline$x$ & $\mathrm{~F}$ & GV036 & - & G & - & - & - & $A$ & - & KY404195 \\
\hline$x$ & $\mathrm{~N}$ & GV567 & - & G & - & - & - & $A$ & - & JN181070 \\
\hline$x$ & $\mathrm{~N}$ & GV898 & - & G & - & - & - & A & - & MK341075 \\
\hline$Y$ & $\mathrm{~F}$ & GV450 & - & G & - & - & - & - & - & KC800983 \\
\hline $\mathrm{Y}$ & $\mathrm{N}$ & GV566 & - & G & - & - & - & - & - & KC800983 \\
\hline W & M & GV348 & - & - & - & - & - & A & - & EU839847 \\
\hline- & $\mathrm{N}$ & GV320 & C & - & - & - & C & $A$ & - & MK341074b \\
\hline \multicolumn{11}{|c|}{ I. frontalis } \\
\hline- & $\mathrm{N}$ & GV1104 & C & - & - & - & $\mathrm{C}$ & $A$ & - & MK341076 \\
\hline
\end{tabular}

All piroplasm 18S rRNA sequences were identical to others previously reported. Thus, B. venatorum sequences showed a $100 \%$ homology to that obtained from an I. ricinus tick in Spain (KM289158), B. microti sequences were identical to that from a USA human pathogenic lineage (XR_002459986) whereas Theileria sp. ОT3 sequence matched with that from sheep in China (KF470868). In addition, all B. venatorum ITS1-sequences were identical to that obtained from an I. ricinus in Germany (HM113372). In contrast, B. microti ITS1-sequences (MN726523) showed a maximum similarity of $96 \%$ with other B. microti sequences (AF510197-AF510198) and a 97\% homology with a sequence deposited as Babesia muratovi (AF510202). Although Theileria sp. OT3 ITS1sequence had bad quality and could not be properly corrected, the percentage of identity with other Theileria sp. OT3 sequences (KF470865 to KF470867) was $90 \%$. 


\section{Discussion}

Our results revealed the presence of Anaplasma, Babesia and Theileria species in questing ticks from the northwest of Spain although the prevalence found were lower than $2 \%$.

The percentage of I. ricinus positive to A. phagocytophilum was similar to those $(0.4 \%-0.6 \%)$ reported in questing specimens of this tick species from some European countries such as Hungary, Slovenia and The Netherlands [2, 32, 33]. However, our data contrast with previous investigations performed in northern Spain where the percentage of A. phagocytophilum positive questing I. ricinus ranged from 5.6-20.5\% [21]. Similarly, prevalence ranging between 1.9\% and $23.6 \%$ were detected in questing I. ricinus collected in most European countries $[1,5,13,34]$. These noticeable differences among the prevalence of $A$. phagocytphilum in I. ricinus throughout Europe may be mainly related to the presence and abundance of reservoirs and susceptible hosts in these areas, although other variables such as the season of study or the number of ticks analysed must be also considered.

A high heterogeneity of A. phagocytophilum groEL-sequences was found (Table 3 ). Nevertheless, all those single nucleotide polymorphisms do not imply changes in the amino acid sequence except for a single sequence belonging to clade I (GV348) which showed a thymine at the nucleotide position 724 resulting in a change in the codified amino acid (Ala to Ser). This mutation has been observed in A. phagocytophilum variants associated to human or animal clinical cases [10,35]. In addition, three different variants of A. phagocytophilum were detected at the 16S rRNA gene (Table 3). The most prevalent variants found, "Y" and " $X$ ", are currently considered apathogenic $[12,14]$; both variants were the most frequently detected in questing ticks and ticks feeding on both red deer and roe deer from Germany [14] as well as in roe deer from Spain [23]. Variant "W" has been previously found on I. ricinus and some mammalian species, mainly domestic and wild ungulates and it has been identified as pathogenic for cattle and sheep $[12,14,36,37]$. This variant was detected in sample GV348, so both molecular markers (groEL and 16S rRNA) indicate that this strain may have zoonotic potential $[10,35]$.

Previous studies performed in Spain have reported the presence of A. phagocytophilum human-pathogenic strains in both questing I. ricinus and blood from roe deer [22-24] and human anaplasmosis cases have been also reported in this country [22]. Although sequence analysis at groEL and 16S rRNA genes does not provide complete information about A. phagocytophilum ecotypes [38] these results provide useful information about A. phagocytophilum pathogenic potential.

Although Ca. N. mikurensis has been found in free-living I. ricinus from several European countries with prevalence ranging from $0.1-24.2 \%$ [4, 8, 39], this pathogen was not detected in the present study. In Spain, in fact, Ca. N. mikurensis was only identified in two feeding I. ricinus males collected from a cow in a northern area [24]; however, neither positive questing ticks nor human cases were currently reported [24]. Since a significant number of I. ricinus was analysed in the present study, our results suggest that Ca. N. mikurensis is not present or exists with a very low percentage in free-living ticks from north-western Spain. However, further studies are needed since spreading of tick-borne diseases depends on environmental, socio-economic and demographic factors, among others [40].

The prevalence of Babesia spp. found in questing I. ricinus from the studied area was consistent with those found in previous studies carried out in Spain where a $0.5 \%$ of I. ricinus was positive [25]; in contrast, the percentage of I. ricinus positive to Theileria was lower than that found in the previous study (8.3\%) [25]. Our data confirm the results reported in other European countries, since the prevalence of both pathogens is usually around $2 \%$ in questing I. ricinus [1, 41 , 42]. Exceptionally, higher Babesia prevalences have been detected in questing ticks, even above $50 \%$, that could be the consequence of high-density tick populations in sampled areas [43]. The piroplasm species identified in the present study and their diversity were different to those previously reported in I. ricinus from Spain [25] where the most prevalent piroplasms were Theileria ovis followed by Theileria sp. OT3, Theileria annulata and Theileria equi-like; the presence of Babesia spp. was limited since a single isolate of B. caballi, Babesia bigemina, Babesia ovis and Babesia major were identified. These differences could be related to the existing population host in the studied areas [42] since that investigation [25] was performed in a mountainous area from northern Spain where ovine livestock is abundant.

Both Babesia species identified in the present study are considered zoonotic as well as emerging pathogens with special interest in human health. Babesia venatorum, the most prevalent piroplasm in the present study, is frequent in its main vector, I. ricinus [44]. The prevalence found in our study was consistent with those reported $(0.3 \%-1 \%)$ in I. ricinus from Europe [41, 42]. Babesia microti has been detected in European I. ricinus, which could play an important role in the transmission and maintenance of this Babesia species with a prevalence ranging from $0.5-3 \%$ [41, 42]. Although B. microti was recently detected in an immunocompetent patient in Spain [45], it is worth noting that not all B. microti can infect humans. Four lineages of B. microti have been described [46] and only some variants of the USA-type are associated with human disease; thus, it has been suggested that most European cases of babesiosis caused by B. microti may be imported [47]. For this reason, the finding of B. microti in questing I. ricinus from north-western Spain may have a limited impact on human health.

It was suggested that both Babesia species showed a clear distribution pattern in I. ricinus from Europe [15]. Thus, I. ricinus from Eastern Europe are more frequently infected with B. microti, whereas B. venatorum infection is more common in ticks from western and northern Europe; Germany is considered a transitory area where I. ricinus presents similar rates of infection by both pathogens [15]. This distribution has been related to the distribution of their main vectors and reservoirs in these areas since $B$. venatorum have been also detected in some wild ungulates such as roe deer (Capreolus capreolus) [48, 49] and mouflons (Ovis aries musimon) [36] and B. microti is closely related to the distribution of its main host, some Microtus species such as Microtus agrestis which is a more specialist species than deer [50].

Only two I. ricinus ticks were positive to Theileria sp. OT3 (0.2\%), being the second report of this pathogen in I. ricinus ticks [25]. Since its main vector remains unknown [51], further studies to determine the role of I. ricinus in the transmission of this piroplasm should be performed. This piroplasm has been detected in European wild ungulates such as roe deer, red deer (Cervus elaphus), fallow deer (Dama dama) and chamois (Rupicapra rupicapra) [45, 52] as well as in 
domestic ruminants such as sheep and goats [48]; however, it has been previously detected only in questing Haemaphysalis punctata and I. ricinus with prevalences of $3.6 \%$ and $1.6 \%$, respectively [25].

The present study provides data on the presence of A. phagocytophilum, Ca. N. mikurensis and piroplasms in I. frontalis and I. acuminatus. In this respect, available information on the prevalence of pathogens in those tick species is limited and restricted to a low number of specimens. Our results are consistent with the absence or low prevalence of pathogens previously reported in I. frontalis specimens collected from birds and nest boxes since it shows endophilic behaviour and all its life stages feed mainly on birds [53]; thus, only the $2.3 \%$ and $3.6 \%$ of the specimens analysed were positive to Anaplasma bovis and A. phagocytophilum, respectively [54] and Ca. N. mikurensis has been also detected in one I. frontalis specimen feeding on a common blackbird (Turdus merula) from Russia [55]. In addition, only one investigation analysed the presence of piroplasms in I. frontalis but no positive specimens were detected [56]. It is worth noting that the close relationship between this tick species and birds hampers the transmission of those pathogens to both humans and other animals [53] suggesting a low impact on human health. Regarding I. acuminatus, it has been reported that may be involved in the endophilic cycle of some pathogens such as Borrelia afzelii, Borrelia valaisiana, Coxiella burnetii, Francisella tularensis and Rickettsia helvetica [35], although there is a lack of information concerning the vectorial capacity of this tick species [53] and no association with Anaplasma spp. or Ca. N. mikurensis has been reported up-to-now. Only one study on the presence of Babesia DNA in questing I. acuminatus was performed, although only three specimens were tested and all were negative [57].

Anaplasma phagocytophilum and Ca. N. mikurensis infection has been also reported in Dermacentor ticks such as Dermacentor reticulatus [8]; in contrast, only the former pathogen was currently identified in D. marginatus [1]. However, the vector capacity of both Dermacentor species for the transmission of A. phagocytophilum and Ca. N. mikurensis remains unknown [8]. Current available data suggest a lower prevalence of both pathogens in Dermacentor spp. than in I. ricinus; since our data show a low percentage of positive I. ricinus it is reasonable that no positive Dermacentor spp. were found. Nevertheless, further studies are needed to determine the real situation of both pathogens in Dermacentor ticks from NW Spain. Although both Dermacentor species are competent vectors of some Babesia and Theileria species such as B. caballi and T. equi [58], no specimens resulted positive. Some authors have detected Dermacentor positive to Babesia spp. and Theileria spp. in some European countries such as Slovakia, France and Poland with prevalences up to 5\% [1]. In Spain, Babesia and Theileria positive questing Dermacentor were previously reported [25] and seven piroplasm species were identified, namely Theileria equi, Theileria sp. OT1, Theileria annae, Babesia canis, Babesia bigemina, Babesia divergens and Babesia caballi-like; however, the number of processed Dermacentor spp. was higher $(n=97)$ than in our study. In addition, although B. microti has been previously detected in questing D. reticulatus ticks [15], the role of this tick species as a vector of this piroplasm is currently unknown.

\section{Conclusions}

Our results revealed that a low percentage of I. ricinus from northwest Spain were infected with A. phagocytophilum and piroplasms, while Ca. N. mikurensis was not detected in I. ricinus pools. Nevertheless, one of the A. phagocytophilum positive samples was similar to a variant associated to human and/or animal clinical cases through the study of groEL and 16S rRNA genes. In addition, all the Babesia species detected (B. venatorum and B. microti) are considered pathogenic for humans. Thus, these data suggest that there is a risk of acquiring zoonotic A. phagocytophilum and piroplasms in the studied area. In addition, the finding of Theileria sp. OT3 in questing I. ricinus is especially interesting since its main vector has not been currently identified; consequently, further investigations are needed to unravel the role of I. ricinus in the transmission of this Theileria species.

\section{Declarations}

\section{Ethics approval and consent to participate}

Not applicable.

\section{Consent for publication}

All authors of the manuscript have read and agreed to its content, approving the text for submission.

\section{Availability of data and material}

All data are presented in the manuscript.

\section{Competing interests}

The authors declare that they have no competing interests.

\section{Funding}

This research was supported by a Postdoctoral Research Grant (Xunta de Galicia, Spain) to Susana Remesar and funds from the Program for Consolidating and Structuring Competitive Research Groups (ED431C 2019/04, Xunta de Galicia, Spain).

\section{Authors' contributions}

PDB and PM established the final methods and design. CML, GF and PD assisted with the preliminary design of the study. PD, SR, and AP collected the ticks. SR and DGD identified the ticks. SR and AP performed the PCRs. CML conducted the statistical analysis. SR, PD, and RP prepared the first paper draft. All authors read and approved the final manuscript. 


\section{Acknowledgements}

We would like to thank Eva Cabanelas for her invaluable help in collecting ticks.

\section{References}

1. Bonnet S, de la Fuente J, Nicollet P, Liu X, Madani N, Blanchard B, et al. Prevalence of tick-borne pathogens in adult Dermacentor spp. ticks from nine collection sites in France. Vector Borne Zoonotic Dis. 2013;13:226-236.

2. Egyed L, Elo P, Sreter-Lancz Z, Szell Z, Balogh Z, Sreter T. Seasonal activity and tick-borne pathogen infection rates of Ixodes ricinus ticks in Hungary. Ticks Tick Borne Dis. 2012;3:90-94.

3. Burri C, Dupasquier C, Bastic V, Gern L. Pathogens of emerging tick-borne diseases, Anaplasma phagocytophilum, Rickettsia spp., and Babesia spp., in Ixodes ticks collected from rodents at four sites in Switzerland (Canton of Bern). Vector Borne Zoonotic Dis. 2011;11:939-944.

4. Capelli G, Ravagnan S, Montarsi F, Ciocchetta S, Cazzin S, Porcellato E, et al. Occurrence and identification of risk areas of Ixodes ricinus-borne pathogens: a cost-effectiveness analysis in north-eastern Italy. Parasit Vectors. 2012;5:61.

5. Venclikova K, Betasova L, Sikutova S, Jedlickova P, Hubalek Z, Rudolf I. Human pathogenic borreliae in Ixodes ricinus ticks in natural and urban ecosystem (Czech Republic). Acta Parasitol. 2014;59:717-720.

6. Rizzoli A, Silaghi C, Obiegala A, Rudolf I, Hubálek Z, Földvári G, et al. Ixodes ricinus and its transmitted pathogens in urban and peri-urban areas in Europe: new hazards and relevance for public health. Front Public Health. 2014;1:251.

7. Jahfari S, Fonville M, Hengeveld P, Reusken C, Scholte, EJ, Takken, W, et al. Prevalence of Neoehrlichia mikurensis in ticks and rodents from North-west Europe. Parasit Vectors. 2012;5:74.

8. Silaghi C, Woll D, Mahling M, Pfister K, Pfeffer M. Candidatus Neoehrlichia mikurensis in rodents in an area with sympatric existence of the hard ticks Ixodes ricinus and Dermacentor reticulatus, Germany. Parasit Vectors. 2012;5:285.

9. Stuen S, Moum T, Petrovec M, Schouls LM. Genetic variants of Anaplasma phagocytophilum in Norway. Int J Med Microbiol. 2006;296:164-166.

10. Carpi G, Bertolotti L, Pecchioli E, Cagnacci F, Rizzoli A. Anaplasma phagocytophilum groEL gene heterogeneity in Ixodes ricinus larvae feeding on roe deer in Northeastern Italy. Vector Borne Zoonotic Dis. 2009;9:179-184,

11. Yang J, Liu Z, Niu Q, Liu J, Han R, Liu G, et al. Molecular survey and characterization of a novel Anaplasma species closely related to Anaplasma capra in ticks, northwestern China. Parasit Vectors. 2016;9:603.

12. Silaghi C, Liebisch G, Pfister K. Genetic variants of Anaplasma phagocytophilum from 14 equine granulocytic anaplasmosis cases. Parasit Vectors. $2011 ; 4: 161$.

13. Paulauskas A, Radzijevskaja J, Rosef O. Molecular detection and characterization of Anaplasma phagocytophilum strains. Comp Immunol Microbiol Infect Dis. 2012;35:187-195.

14. Overzier E, Pfister K, Thiel C, Herb I, Mahling M, Silaghi C. Anaplasma phagocytophilum in questing Ixodes ricinus ticks: comparison of prevalences and partial 16S rRNA gene variants in urban, pasture, and natural habitats. Appl Environ Microbiol. 2013;79:1730-4.

15. Wójcik-Fatla A, Zajac V, Sawczyn, A, Cisak E, Dutkiewicz J. Babesia spp. in questing ticks from eastern Poland: prevalence and species diversity. Parasitol Res. 2015;114:3111-3116.

16. Welc-Faleciak R, Pawelczyk A, Radkowski M, Pancewicz SA, Zajkowska J, Sinski E. First report of two asymptomatic cases of human infection with Babesia microti (Franca, 1910) in Poland. Ann Agric Environ Med. 2015;22:51-54.

17. Gray J, Zintl A, Hildebrandt A, Hunfeld KP, Weiss L. Zoonotic babesiosis overview of the disease and novel aspects of pathogen identity. Ticks Tick Borne Dis. 2010;1:3-10.

18. Mans BJ, Pienaar R, Latif AA. A review of Theileria diagnostics and epidemiology. Int J Parasitol Parasites Wildl. 2015;4:104-118.

19. Wise LN, Pelzel-McCluskey AM, Mealey RH, Knowles DP. Equine piroplasmosis. Vet Clin N Am Equine. 2014;30:677-693.

20. Homer MJ, Aguilar-Delfin I, Telford SR, Krause PJ, Persing DH. Babesiosis. Clin Microbiol Rev. 2000;13:451-469.

21. Ruíz-Fons F, Fernández-de-Mera IG, Acevedo P, Gortázar C, de la Fuente J. Factors driving the abundance of Ixodes ricinus ticks and the prevalence of zoonotic I. ricinus-borne pathogens in natural foci. Appl Environ Microbiol. 2012;78:2669-2676.

22. Portillo A, Santos AS, Santibáñez S, Pérez-Martínez L, Blanco JR, Ibarra V, et al. Detection of a non-pathogenic variant of Anaplasma phagocytophilum in Ixodes ricinus from La Rioja, Spain. In: Oteo JA, Hechemy KE, Raoult DA, Silverman DJ, Blanco JR, editors. Rickettsioses: from Genome to Proteome, Pathobiology, and Rickettsiae as an International Threat. Wiley-Blackwell; 2005. p. 333-336.

23. Remesar S, Díaz P, Prieto A, García-Dios D, Fernández G, López CM, et al. Prevalence and molecular characterization of Anaplasma phagocytophilum in roe deer (Capreolus capreolus) from Spain. Ticks Tick Borne Dis. 2019; in press:101351.

24. Palomar AM, García-Álvarez L, Santibánez S, Portillo A, Oteo JA. Detection of tick-borne 'Candidatus Neoehrlichia mikurensis' and Anaplasma phagocytophilum in Spain in 2013. Parasit Vectors. 2014;7:57.

25. García-Sanmartín J, Barandika JF, Juste RA, García-Pérez AL, Hurtado A. Distribution and molecular detection of Theileria and Babesia in questing ticks from northern Spain. Med Vet Entomol. 2008;22:318-325.

26. Remesar S, Díaz P, Venzal JM, Pérez-Creo A, Prieto A, Estrada-Peña A, et al. Tick species diversity and population dynamics of Ixodes ricinus in Galicia (north-western Spain), Ticks Tick Borne Dis. 2019;10:132-137.

27. Pérez-Eid C. Les tiques. Identification, biologie, importance médicale et vétérinarire. Paris: TEC \& DOC. Lavoisier; 2007. 
28. Chen SM, Dumler JS, Bakken JS, Walker DH. Identification of a granulocytotropic Ehrlichia species as the etiologic agent of human-disease. J Clin Microbiol Infect. 1994;32:589-595.

29. Sumner JW, Nicholson WL, Massung RF. PCR amplification and comparison of nucleotide sequences from the groESL heat shock operon of Ehrlichia species. J Clin Microbiol Infect. 1997;35:2087-2092.

30. Williams CJ, Moffitt CM. Estimation of pathogen prevalence in pooled samples using maximum likelihood methods and open-source software. J Aquat Anim Health. 2005;17(4):386-391.

31. R Core Team. R: A Language and Environment for Statistical Computing. 2018. https://www.R-project.org/

32. Wielinga PR, Gaasenbeek C, Fonville M, de Boer A, de Vries A, Dimmers W, et al. Longitudinal analysis of tick densities and Borrelia, Anaplasma, and Ehrlichia infections of Ixodes ricinus ticks in different habitat areas in the Netherlands. Appl. Environ. Microbiol. 2006;72:7594-7601.

33. Smrdel KS, Serdt M, Duh D, Knap N, Zupanc TA. Anaplasma phagocytophilum in ticks in Slovenia. Parasit Vectors. $2010 ; 3: 102$.

34. Skarphedinsson S, Lyholm BF, Ljungberg M, Sogaard P, Kolmos HJ, Nielsen LP. Detection and identification of Anaplasma phagocytophilum, Borrelia burgdorferi, and Rickettsia helvetica in Danish Ixodes ricinus ticks. APMIS. 2007;115:225-230.

35. Petrovec M, Bidovec A, Sumner JW, Nicholson WL, Childs JE, Avsic-Zupanc T. Infection with Anaplasma phagocytophila in cervids from Slovenia: evidence of two genotypic lineages. Wien Klin Wochenschr. 2002;114:641-647.

36. Kauffmann M, Rehbein S, Hamel D, Lutz W, Heddergott M, Pfister K. Anaplasma phagocytophilum and Babesia spp. in roe deer (Capreolus capreolus), fallow deer (Dama dama) and mouflon (Ovis musimon) in Germany. Mol Cell Probes. 2017;31:46-54.

37. Liz JS, Sumner JW, Pfister K, Brossard M. PCR detection and serological evidence of granulocytic ehrlichial infection in roe deer (Capreolus capreolus) and chamois (Rupicapra rupicapra). J Clin Microbiol Infect. 2002;40:892-897.

38. Battilani M, De Arcangeli S, Balboni A, Dondi F.Genetic diversity and molecular epidemiology of Anaplasma. Infect Genet Evol. 2017;49:195-211.

39. Szekeres S, Coipan EC, Rigo K, Majoros G, Jahfari S, Sprong H, et al. Candidatus Neoehrlichia mikurensis and Anaplasma phagocytophilum in natural rodent and tick communities in Southern Hungary. Ticks Tick Borne Dis. 2015;6:111-116.

40. Medlock JM, Hansford KM, Bormane A, Derdakova M, Estrada-Peña A, George JC, et al. Driving forces for changes in geographical distribution of Ixodes ricinus ticks in Europe. Parasit Vectors. 2013:6.1.

41. Reye AL, Stegniy V, Mishaeva NP, Velhin S, Hubschen JM, Ignatyev G, et al. Prevalence of tick-borne pathogens in Ixodes ricinus and Dermacentor reticulatus ticks from different geographical locations in Belarus. Plos One. 2013;8(1):e54476.

42. Karlsson ME, Andersson MO. Babesia species in questing Ixodes ricinus, Sweden. Ticks Tick Borne Dis. 2016;7:10-12.

43. Blaschitz M, Narodoslavsky-Gfoller M, Kanzler M, Stanek G, Walochnik J. Babesia species occurring in Austrian Ixodes ricinus ticks. Appl Environ Microbiol. 2008;74:4841-4846.

44. Malandrin L, Jouglin M, Sun Y, Brisseau N, Chauvin A. Redescription of Babesia capreoli (Enigk and Friedhoff, 1962) from roe deer (Capreolus capreolus): Isolation, cultivation, host specificity, molecular characterisation and differentiation from Babesia divergens. Int. J. Parasitol. 2010;40:277-284.

45. Arsuaga M, González LM, Lobo CA, de la Calle F, Bautista JM, Azcárate IG, et al. First report of Babesia microti-caused babesiosis in Spain. Vector Borne Zoonotic Dis. 2016;16(10):677-679.

46. Schnittger L, Rodriguez AE, Florin-Christensen M, Morrison DA. Babesia: A world emerging. Infect Genet Evol. 2012;12:1788-1809.

47. Hildebrandt A, Hunfeld KP, Baier M, Krumbholz A, Sachse S, Lorenzen T. First confirmed autochthonous case of human Babesia microti infection in Europe. Int J Med Microbiol. 2007;297:95-95.

48. Zanet S, Trisciuoglio A, Bottero E, de Mera IGF, Gortázar C, Carpignano MG, et al. Piroplasmosis in wildlife: Babesia and Theileria affecting free-ranging ungulates and carnivores in the Italian Alps. Parasite Vector. 2014;7:70.

49. Remesar S, Díaz P, Prieto A, Markina F, Díaz-Cao JM, López-Lorenzo G, et al Prevalence and distribution of Babesia and Theileria species in roe deer from Spain. Int J Parasitol Parasites Wildl. 2019;9:195-201.

50. Foppa IM, Krause PJ, Spielman A, Goethert H, Gern L, Brand B, et al. Entomologic and serologic evidence of zoonotic transmission of Babesia microti, eastern Switzerland. Emerg Infec Dis. 2002;8:722-726.

51. Giangaspero A, Marangi M, Papini R, Paoletti B, Wijnveld M, Jongejan F. Theileria sp. OT3 and other tick-borne pathogens in sheep and ticks in Italy: Molecular characterization and phylogeny. Ticks Tick-Borne Dis. 2015;6:75-83.

52. Pereira A, Parreira R, Nunes M, Casadinho A, Vieira ML, Campino L, et al. Molecular detection of tick-borne bacteria and protozoa in cervids and wild boars from Portugal. Parasite Vector. 2016;9:251.

53. Estrada-Peña A, Mihalca A, Petney TN. Ticks of Europe and North Africa. ed. Springer. Gewerbestrasse, Cham, Switzerland; 2017.

54. Heylen D, Fonville M, van Leeuwen AD, Stroo A, Duisterwinkel M, van Wieren S, et al. Pathogen communities of songbird-derived ticks in Europe's low countries. Parasit Vectors. 2017;10:497.

55. Movila A, Alekseev AN, Dubinina HV, Toderas I. Detection of tick-borne pathogens in ticks from migratory birds in the Baltic region of Russia. Med Vet Entomol. 2013;27:113-117.

56. Monks D, Fisher M, Forbes NA. Ixodes frontalis and avian tick-related syndrome in the United Kingdom. J Small Anim Pract. 2006;47:451-455.

57. Aureli S, Galuppi R, Ostanello F, Foley JE, Bonoli C, Rejmanek D, et al. Abundance of questing ticks and molecular evidence for pathogens in ticks in three parks of Emilia-Romagna region of Northern Italy. Ann Agric Environ Med. 2015;22:459-466.

58. Jongejan F, Ringenier M, Putting M, Berger L, Burgers S, Kortekaas R, et al. Novel foci of Dermacentor reticulatus ticks infected with Babesia canis and Babesia caballi in the Netherlands and in Belgium. Parasit Vectors. 2015;8:232.

Page 9/10 
59. Zeidner NS, Burkot TR, Massung R, Nicholson WL, Dolan MC, Rutherford JS, et al. Transmission of the agent of human granulocytic ehrlichiosis by Ixodes spinipalpis ticks: evidence of an enzootic cycle of dual infection with Borrelia burgdorferi in Northern Colorado. J Infect Dis. 2000;182:616-9.

60. Zahler M, Rinder H, Schein E, Gothe R. Detection of a new pathogenic Babesia microtilike species in dogs. Vet Parasitol. 2000;89:241-248.

61. da Silveira JAG, Rabelo EML, Ribeiro MFB. Detection of Theileria and Babesia in brown brocket deer (Mazama gouazoubira) and marsh deer (Blastocerus dichotomus) in the State of Minas Gerais, Brazil. Vet Parasitol. 2011;177:61-66.

62. Bajer A, Alsarraf M, Bednarska M, Mohallal EME, Mierzejewska EJ, Behnke-Borowczyk J, et al. Babesia behnkei sp nov., a novel Babesia species infecting isolated populations of Wagner's gerbil, Dipodillus dasyurus, from the Sinai Mountains, Egypt. Parasite Vector. 2014;7:572.

\section{Supplementary Files}

This is a list of supplementary files associated with this preprint. Click to download.

- GraphicalAbstract.jpg 